\title{
Fatigue and Damage Tolerance, Prediction of Crack Propagation on Plate Using Paris Equation and Walker Equation
}

\author{
Andry Renaldy Pandie ${ }^{1}$, A.R. Yudiana ${ }^{2}$, Hermansah $^{3}$ \\ \{pandie-andry@ed.tmu.ac.jp ${ }^{1}$ \} \\ Ph.D student at Department of Aeronautics and Astronautics, Tokyo Metropolitan University, \\ 6-6 Asahigaoka, Hino, Tokyo 191-0065, Japan ${ }^{1}$, Department of Aerospace Engineering, \\ Sekolah Tinggi Teknologi Adisutjipto, Yogyakarta ${ }^{2,3}$
}

\begin{abstract}
Metals subjected to repetitive stresses and loads will be damaged at certain cycle stresses which cause fracture and failure. This failure was marked by a defect. To predict the magnitude of the propagation of the crack until the failure of the structure is used the Paris equation and the Walker equation to solve it. In this article, the boundaries used to determine a structure fail with the initial crack length known to consist of limits: $a \geq 0.8 W, \sigma_{\text {net } \max } \geq \sigma_{y}$, $K_{\max } \geq \sigma_{y}$, and $K_{\max } \geq K_{I C}$. The method used to solve this case is the study of literature and using the Matlab software whose steps are contained in the flow diagram. The material to be analyzed and predicted for the addition of cracks is the aluminum series Al-2219-T87 with geometry a $(70 \mathrm{E}-3 \mathrm{~m}), \mathrm{W}(150 \mathrm{E}-3 \mathrm{~m})$, $\sigma_{\max }(20 \mathrm{MPa}), \sigma_{\min }(12,13,14,16 \mathrm{MPa})$. After analysis, conclusions are obtained: ${ }^{1}$ Analysis using the Walker equation gives the value of fatigue life or the number of failed cycles that are less than the Paris equation, this is because Walker takes into account the stress ratio, ${ }^{2}$ The average percentage change in the cycle in the Paris equation starting from $\sigma_{\min } 12$ to 16 is $55.52 \%$, ${ }^{3}$ The average percentage of cycle changes in the Walker equation starting from $\sigma_{\min }$ 12 to 16 is $39.28 \%,{ }^{4}$ The average percentage of cycle changes in the Paris and Walker equations starting from $\sigma_{\min } 12$ to 16 is $70 \%,{ }^{5}$ Fatigue life will increase if the value of $\mathrm{R}$ gets closer to the value 1,8 the structure fails when $(\mathrm{a}=120$ $\mathrm{mm})$.
\end{abstract}

Keywords: Stress; Failure; Paris; Walker; Fatigue; Crack

\section{Introduction}

On April 28, 1988 at 1346, Boeing 737-200, N73711 aircraft operated by Aloha Airlines Inc., with flight number 243 experienced explosive decompression and failure of structures at an altitude of $24000 \mathrm{ft}$ when flying from Hilo - Honolulu, Hawaii, USA. It is estimated to be $18 \mathrm{ft}$ long in the skin cabin and its structure after the cabin entrance is released while flying. The area where the skin structure is released starts from the aft body station 360 to the body station 540, and the circular section starts from the top of the left side of the S-15L through the 
cabin ceiling and goes to the lower right up to the $\mathrm{S}-10 \mathrm{R}$ belt window. The release of this skin causes some parts to experience minor damage, such as the leading edge of both wings, horizontal stabilizer and vertical stabilizer, inlet cowls on both engines, and first stage on the fan blades of the two engines, the start level cable that flows the fuel. Damage to the loose section indicates that failure starts from the left fuselage, where the defect propagates longitudinally in fuselage [1].

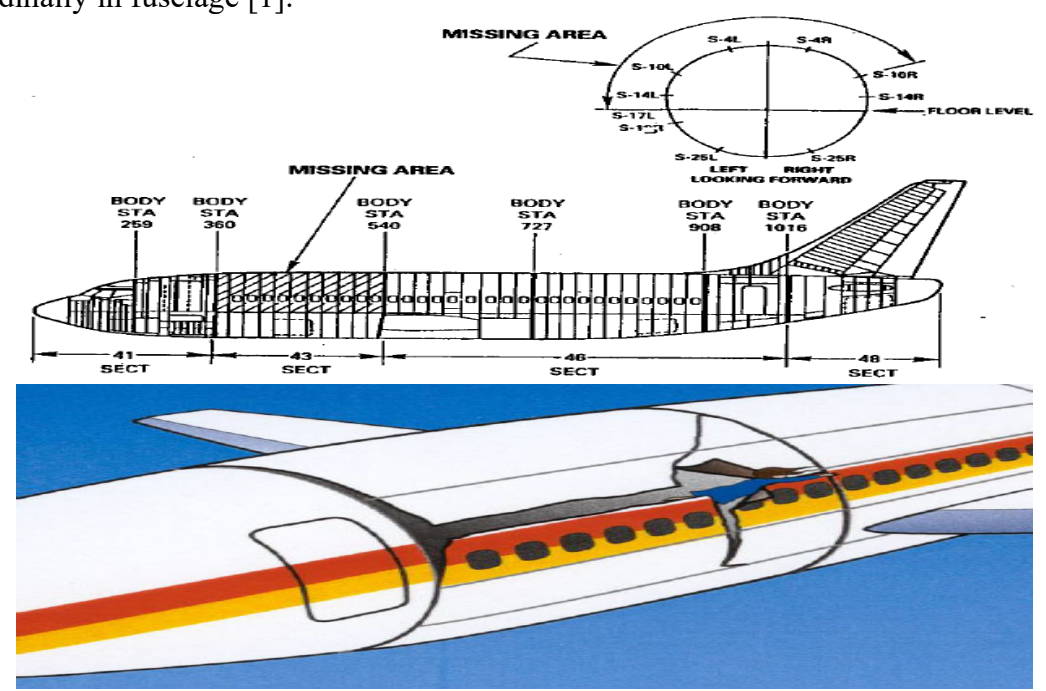

Fig. 1. Structural failure of Aloha Airlines with flight number 243 [1]

The structure of airplanes, especially civil aircraft, is still largely made of metal, although now there have been developments for the use of composites whose numbers have not replaced the role of metals. Metals subject to repetitive stresses and loads will be damaged at certain cycle stresses which cause fracture and failure [2]. This failure was marked by a defect. This defect can affect the structure of the material because the material has passed through the fatigue point. Fatigue failures are the behavior of metals that fail because of repeated variable stresses with a certain value (usually under the yield stress of material), which generally occurs after a long period of usage. Fatigue failure is increasingly prominent along with technological developments, one of which is the development of aircraft which will experience repeated loads and vibrations. Repeated loads and vibrations are what increase failure in aircraft structures.

Fatigue failure arising from the structure of the aircraft must be predictable at the time of design and selection of structural materials so as not to endanger safety when operated. One of these fatigue failures can be approached using the initial cracks that occur in the structure. The initial crack that occurs will continue to increase in crack along with changes in the load / stress imposed on the structure. Therefore, it is necessary to predict the magnitude of crack propagation that occurs until the structure fails. To predict the magnitude of the propagation of the crack until the failure of the structure, the Paris equation and the Walker equation are used. In the Paris equation, the value of the stress ratio is not calculated. Whereas in the Walker equation, the stress ratio is calculated. In this article, the boundaries used to determine a structure fail with the initial crack length known to consist of limits: 

a. $a \geq 0.8 W$
b. $\sigma_{\text {net } \max } \geq \sigma_{y}$
c. $K_{\max } \geq \sigma_{y}$
d. $K_{\max } \geq K_{I C}$

\section{Method and Basic Theory}

Fracture / failure is a problem that is commonly found in every structure designed and made by humans. Current structural problems are increasingly complex and need solutions to problem solving, which is evident from the large number of aircraft that have crashed due to structural failure [3]. Common causes often encountered in structural failures fall into one of the following categories:

a. Negligence during the design, construction or production and operation of the structure.

b. Determination of design or new material where the results are not as expected.

There are three basic factors that cause fatigue failure, namely the maximum tensile stress, variation or stress fluctuation, and the stress application cycle. In addition to these three basic factors, there are still several other factors that influence, namely stress concentration, corrosion, temperature, excess material, metallurgical structure, and combination stress [2]. The following is the process of basic changes that occur in structures that experience repeated stresses:

a. The beginning of crack formation - the initial formation of failure caused by scratches, dent, corrosion or impact.

b. Propagation / crack growth stage 1 (slip band crack growth) - propagation of cracks in fields having high shear stresses.

c. Crack propagation stage 2 - crack propagation in fields having high tensile stress / crack propagation perpendicular to the maximum tensile stress.

d. Ultimate ductile failure - occurs when the crack reaches a length that is large enough so that the remaining cross section / field is no longer able to withstand the load that occurs [2].

In generally there are 3 phases in damage or failure due to fatigue, namely crack initiation, crack propagation, and fracture [5]. Airplane structural components can experience loading in several variations of loads such as load fluctuations, strain fluctuations or temperature fluctuations. In fact, it is not uncommon for construction to experience combined stress or contamination with a corrosive environment which will certainly cause a construction to be more threatened by safety. In generally there are three cycles that can show a fatigue stress cycle, namely:

a. Stress fluctuations occur from zero average stress with a reversed stress cycle.

b. Stress fluctuations start above the zero average line with a repeated stress cycle.

c. Random stress cycle. 

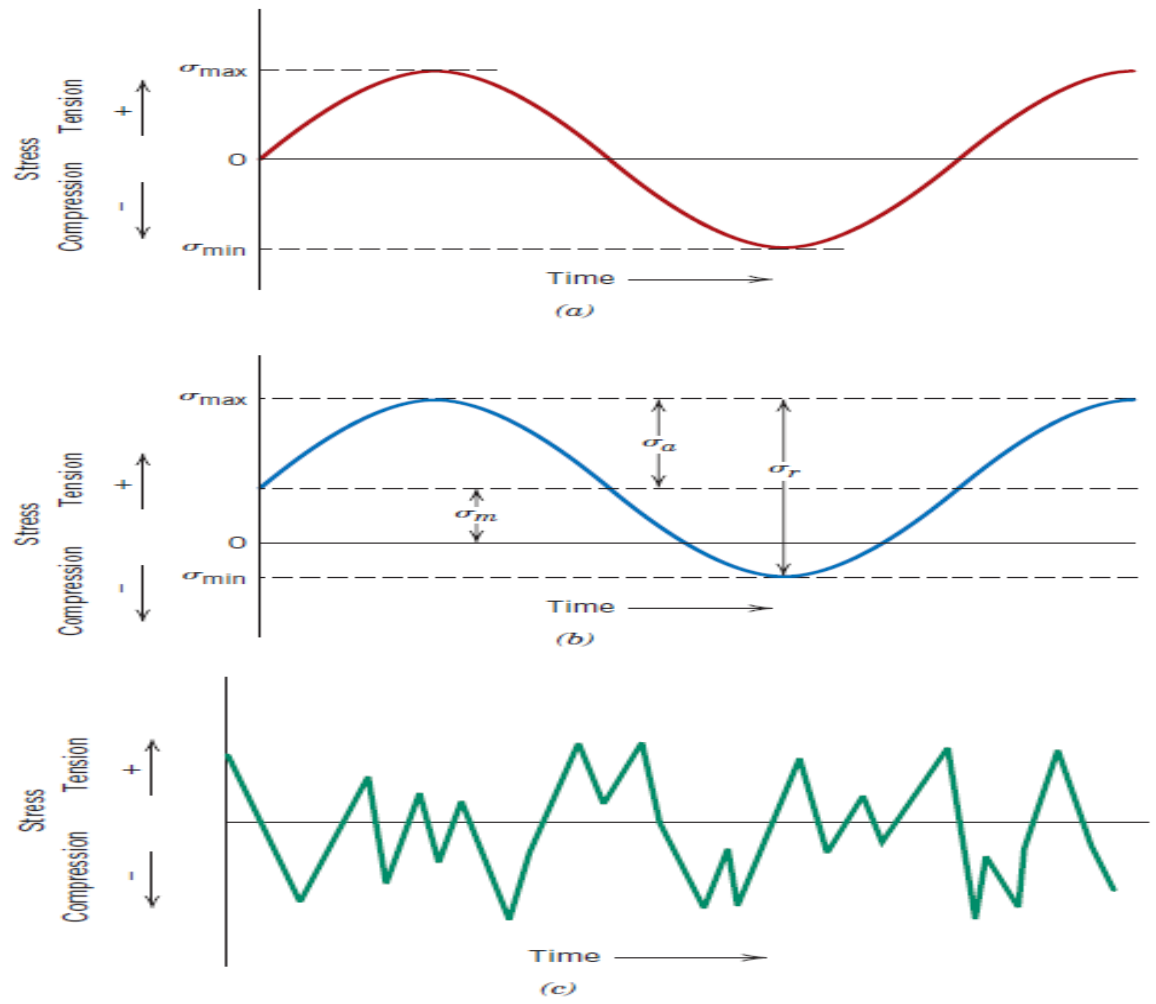

Fig. 2. Fatigue stress cycle [4]

The following equation for the stress cycle graphs above:

$\sigma_{m}=\frac{\sigma_{\max }+\sigma_{\min }}{2}$

$\Delta \sigma=\sigma_{r}=\sigma_{\max }-\sigma_{\min }$

$\sigma_{a}=\frac{\sigma_{r}}{2}=\frac{\sigma_{\max }-\sigma_{\min }}{2}$

$R=\frac{\sigma_{\min }}{\sigma_{\max }}$ 
Fatigue data is usually presented in a stress and cycle curve, where the stress is $\mathrm{S}$ and the cycle is $\mathrm{N}$. The number of cycles is a cycle ranging from cracking to crack propagation.

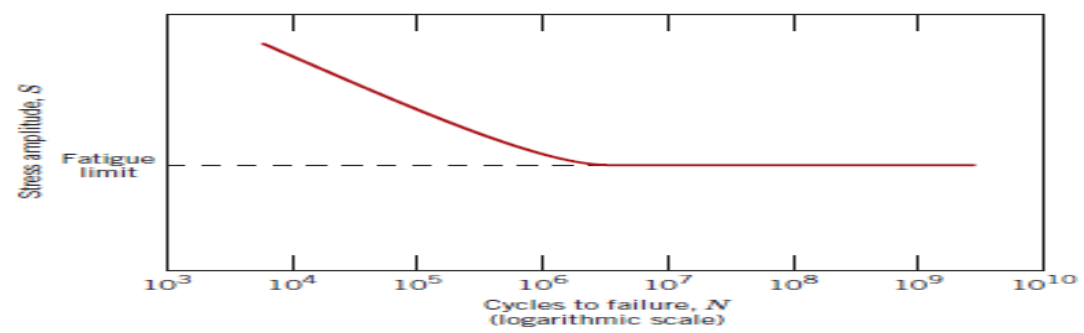

(a)

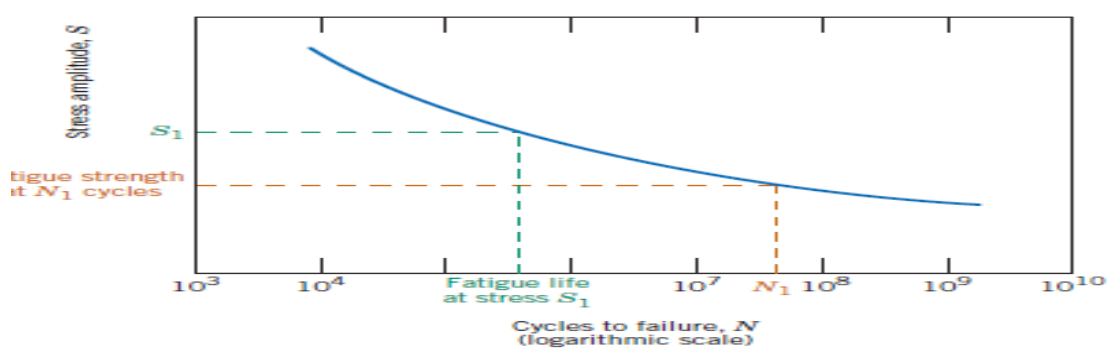

Fig. 3. S-N curve [4]

It can be seen that if the stress drops then the number of cycles for failure to increase, whereas if the stress rises, the number of cycles will decrease (Figure 3). For fatigue life itself, there are several factors that influence it, namely:

a. The stress concentration - the trigger for stress concentrations such as fillets, notches, etc. will cause a decrease in fatigue life.

b. Material dimension / size - if the size of the specimen increases, the fatigue resistance sometimes decreases. This is because fatigue failure usually starts from the surface. So, if the additional size is done then it gives the possibility of causing the existence of defects. As a result, the crack began with the defect.

c. Surface effects - fatigue resistance is strongly influenced by surface conditions. The surface conditions are surface properties such as surface treatment such as surface hardening and residual surface tension. The effects of surface finishing or surface roughness qualitatively also affect the fatigue resistance of a material. Conversely the surface hardening process can increase fatigue resistance. Residual stress, especially compressive residual stress, will provide increased fatigue resistance. This residual stress can be developed by performing plastic deformations that are not uniform in a cross section.

d. Mean stress - mean stress also affects fatigue resistance. This stress is indicated by the amplitude of the stress expressed by the stress ratio. If the tensile amplitude is equal to the amplitude of the compressive stress. If the $\mathrm{R}$ value tends to be positive, the fatigue resistance will decrease.

Crack growth is the change in the length of the crack to the loading cycle that occurs. In this stage the crack grows and spreads to reach a critical size. From crack propagation data, fatigue life predictions can be developed. From the concept of fracture mechanics, the crack 
growth rate is expressed by $\frac{d a}{d N}$ which is a function of material properties, crack length, and operating stress. Cracks start from the weakest regions, then develop along with the cycle of loading. To prevent fracture mechanics / mechanical cracking in the material, several design approaches were taken to anticipate it. These approaches include [3]:

a. The approach to using energy standards - is used when cracking occurs when the energy available for crack growth exceeds material resistance.

b. b. Approach to stress intensity - this approach is used to determine the stress distribution at the crack tip of the material. To calculate the stress distribution, it is necessary to know the value of stress intensity factor $\left(\mathrm{K}_{\mathrm{I}}\right)$ formulated with $\mathrm{K}_{\mathrm{I}}=\sigma \sqrt{\pi \mathrm{a}}$

c. c. Failure tolerance approach - this approach is used to predict material durability based on time variables and crack cracking mechanisms. Crack growth rate has a correlation with stress intensity factors and fracture toughness material. The crack rate is formulated with $\frac{d a}{d N}=C(\Delta K)^{m}$

The fatigue life of a component that has a defect, initial defect, or continuity can be predicted using fracture mechanics developed and widely used both analytically, experimentally and numerically. To evaluate a structure that has flaw, one approach is to predict the age of crack propagation. In fatigue cases, the Linear Elastic Fracture Mechanics (LEFM) method is commonly used. This is because fatigue cases occur in elastic conditions. The parameters used in LEFM consist of:

a. a. Voltage intensity factor $\left(\mathrm{K}_{\mathrm{I}}\right)$ - the $\mathrm{K}_{\mathrm{I}}$ value indicates the strength of a component, or the age of the crack growth and a measure of the magnitude of the stress concentration field around the crack tip. The value of $\mathrm{K}_{\mathrm{I}}$ is a function of the crack length and working stress formulated with $\mathrm{K}_{\mathrm{I}}=\mathrm{Y} \sigma \sqrt{\pi \mathrm{a}}$

b. Material toughness properties (fracture toughness) $\mathrm{K}_{\mathrm{IC}}-$ the $\mathrm{K}_{\mathrm{IC}}$ value is the material toughness properties in resisting crack rates. The nature of the toughness of the material in static conditions is expressed as yield strength or ultimate strength. If value $K_{I}<K_{I C}$ it can be said that a construction is safe. And vice versa if the value of $\mathrm{K}_{\mathrm{I}}$ approaches the value of $\mathrm{K}_{\mathrm{IC}}$ or $K_{I} \geq K_{I C}$ it can be said that a construction will experience a failure / broken [5].

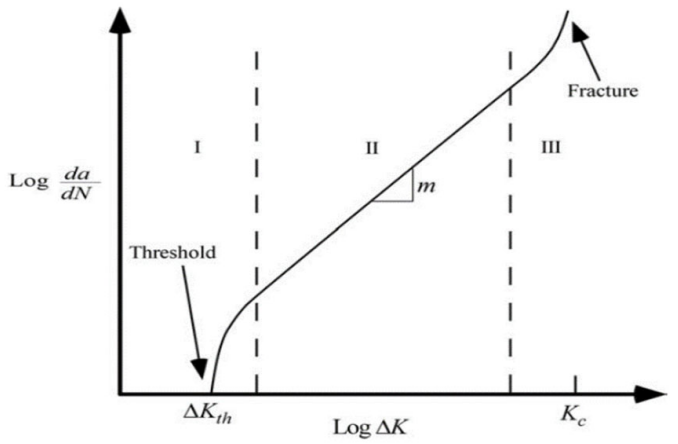

Fig. 4. Type of crack growth on metal [2] 
Caption:

Region I $\rightarrow$ At the threshold, the crack does not increase

Region II $\rightarrow$ Linear region

Region III $\rightarrow$ The rate of increase in cracks will increase rapidly.

In this paper, only calculating the amount of crack propagation that occurs in region I, two equations are used, namely;

\subsection{Paris Equation}

In this equation, the ratio between the maximum stress and the minimum stress is not taken into account. The following are the equations used:

$\Delta \sigma=\sigma_{\max }-\sigma_{\min }$

$\Delta K_{I}=Y \Delta \sigma \sqrt{\pi a}$

$\Delta a=\frac{d a}{d N}=C(\Delta K)^{m}$

$a_{n}=a_{0}+\Delta a$

\subsection{Walker Equation}

$$
R=\frac{\sigma_{\min }}{\sigma_{\max }}
$$

$\Delta \sigma=\sigma_{\max }-\sigma_{\min }$

$\Delta K_{I}=Y \Delta \sigma \sqrt{\pi a}$

$\Delta a=\frac{d a}{d n}=\frac{C(\Delta K)^{m}}{1-R}$

$a_{n}=a_{0}+\Delta a$

2.3 Percentage of difference between $\sigma_{\min }$ in the equation of Paris and Walker

$\% \Delta$ Cycle $=\frac{\left|S \sigma_{A}-S \sigma_{B}\right|}{\frac{1}{2} \times\left(S \sigma_{A}+S \sigma_{B}\right)} \times 100$ 
2.4 Percentage of failed cycle difference between Paris and Walker to Paris with the same $\mathbf{R}$

$\% \Delta$ Cycle $=\frac{\mid \text { ParisCycle }- \text { Wal kerCycle } \mid}{\text { ParisCycle }} \times 100$

\section{Methodology}

The material to be analyzed and predicted for the crack increase is the aluminum Al-2219T87 series which has the following properties [6]:

\begin{tabular}{cccc}
\multicolumn{4}{c}{ Table 1. Properties Al-2219-T87 } \\
\hline $\boldsymbol{\sigma}_{y}(\mathbf{M P a})$ & $\mathbf{K}_{I C}(\mathbf{M P a} \sqrt{\mathbf{m}})$ & $\mathbf{C}$ & $\mathbf{m}$ \\
\hline $\mathbf{3 9 5}$ & 27.3 & $6.27 \mathrm{E}-11$ & 3.3 \\
\hline
\end{tabular}

The plate geometry is as follows:

$$
\begin{array}{ll}
\mathrm{a} & =70 \mathrm{E}-3 \mathrm{~m} \\
\mathrm{~W} & =150 \mathrm{E}-3 \mathrm{~m} \\
\sigma_{\max } & =20 \mathrm{MPa} \\
\sigma_{\min } & =12,13,14,16 \mathrm{MPa}
\end{array}
$$

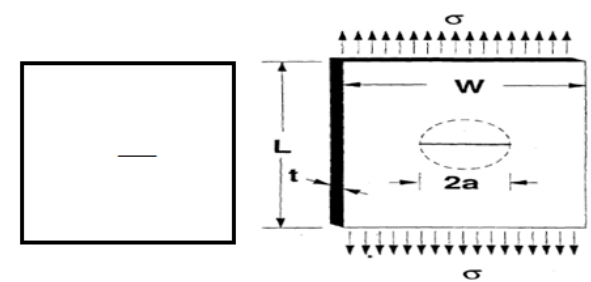

Fig. 5. Plate geometry that predicted the crack propagation

The method used in solving this case is use Matlab software whose steps are outlined in the following flow chart: 


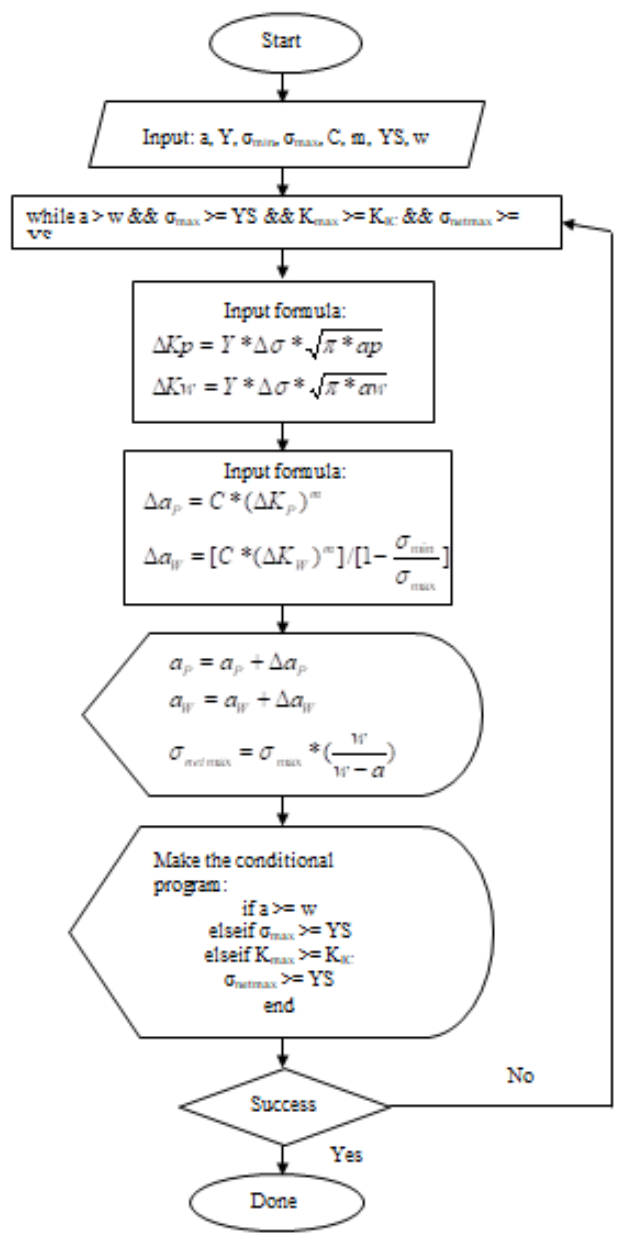

Fig. 6. Flow Chart

\section{Result and Discussion}

Programs that are run in Matlab use parameters:
a. $\mathrm{a}=70 \mathrm{E}-3 \mathrm{~m}$
b. $\mathrm{W}=150 \mathrm{E}-3 \mathrm{~m}$
c. $\sigma_{\max }=20 \mathrm{Mpa} \sqrt{\mathrm{m}}$
d. $\sigma_{\min }=12,13,14,16 \mathrm{Mpa} \sqrt{\mathrm{m}}$
e. $\mathrm{Y}=1$
f. Every increase in cycle 2E5, the value $a_{n}$ displayed
g. Properties owned by Al-2219-T87.
Based on the parameters above, the results are: 


\subsection{Paris Equation}

Table 2. Results in the Paris equation $\left(\sigma_{\max }=20\right.$ and $\left.\sigma_{\min }=12\right)$

\begin{tabular}{cccc}
\hline No & $\mathbf{a n}_{\mathbf{n}}(\mathbf{m})$ & $\mathbf{a n}(\mathbf{m m})$ & $\mathbf{N}$ (Cycle) \\
\hline 1 & $7.00 \mathrm{E}-02$ & 70 & $0.00 \mathrm{E}+00$ \\
4 & 0.12 & $1.20 \mathrm{E}+02$ & $6,466,247$
\end{tabular}

Table 3. Results in the Paris equation $\left(\sigma_{\max }=20\right.$ and $\left.\sigma_{\min }=13\right)$

\begin{tabular}{cccc} 
No & $\mathbf{a}_{\mathbf{n}}(\mathbf{m})$ & $\mathbf{a}_{\mathbf{n}}(\mathbf{m m})$ & $\mathbf{N}$ (Cycle) \\
\hline 1 & $7.00 \mathrm{E}-02$ & 70 & $0.00 \mathrm{E}+00$ \\
52 & 0.12 & 120 & $10,046,753$ \\
\hline
\end{tabular}

Table 4. Results in the Paris equation $\left(\sigma_{\max }=20\right.$ and $\left.\sigma_{\min }=14\right)$

\begin{tabular}{cccc}
\hline No & $\mathbf{a}_{\mathbf{n}}(\mathbf{m})$ & $\left.\mathbf{a}_{\mathbf{n}} \mathbf{( m m}\right)$ & $\mathbf{N}$ (Cycle) \\
\hline 1 & $7.00 \mathrm{E}-02$ & 70 & $0.00 \mathrm{E}+00$ \\
85 & 0.12 & 120 & $16,708,986$ \\
\hline
\end{tabular}

Table 5. Results in the Paris equation $\left(\sigma_{\max }=20\right.$ and $\left.\sigma_{\min }=15\right)$

\begin{tabular}{cccc}
\hline No & $\mathbf{a}_{\mathbf{n}} \mathbf{( m )}$ & $\mathbf{a n}_{\mathbf{n}}(\mathbf{m m})$ & $\mathbf{N}$ (Cycle) \\
\hline 1 & $7.00 \mathrm{E}-02$ & 70 & $0.00 \mathrm{E}+00$ \\
151 & 0.12 & 120 & $30,496,373$ \\
\hline
\end{tabular}

Table 6. Results in the Paris equation $\left(\sigma_{\max }=20\right.$ and $\left.\sigma_{\min }=16\right)$

\begin{tabular}{cccc}
\hline No & $\mathbf{a}_{\mathbf{n}}(\mathbf{m})$ & $\mathbf{a}_{\mathbf{n}}(\mathbf{m m})$ & $\mathbf{N}(\mathbf{C y c l e})$ \\
\hline 1 & $7.00 \mathrm{E}-02$ & 70 & $0.00 \mathrm{E}+00$ \\
320 & 0.12 & $1.20 \mathrm{E}+02$ & $63,687,065$ \\
\hline
\end{tabular}

Table 7. Difference in cycles in the Paris equation with variations of $\sigma_{\min }$

\begin{tabular}{ccccc}
\hline $\mathbf{N o}$ & $\mathbf{1}$ & $\mathbf{2}$ & $\mathbf{3}$ & $\mathbf{4}$ \\
\hline $\mathrm{N}$ & $6,466,247\left(\sigma_{\min } 12\right)$ & $10,046,753\left(\sigma_{\min } 13\right)$ & $16,708,986\left(\sigma_{\min } 14\right)$ & $30,496,373\left(\sigma_{\min } 15\right)$ \\
$\mathrm{N}$ & $10,046,753\left(\sigma_{\min } 13\right)$ & $16,708,986\left(\sigma_{\min } 14\right)$ & $30,496,373\left(\sigma_{\min } 15\right)$ & $63,687,065\left(\sigma_{\min } 16\right)$ \\
$\mathrm{N}$ & $3,580,506$ & $6,662,233$ & $13,787,387$ & $33,190,692$ \\
$\mathrm{~N}$ & \multicolumn{4}{c}{106.2585576} \\
$\%$ & 155.372243 & $(\Delta \mathrm{N} 1+\Delta \mathrm{N} 2+\Delta \mathrm{N} 3+\Delta \mathrm{N} 4) / 4=14,305,204.5$ & \\
\multicolumn{4}{c}{166.3123001} & 182.5148037 \\
\hline
\end{tabular}

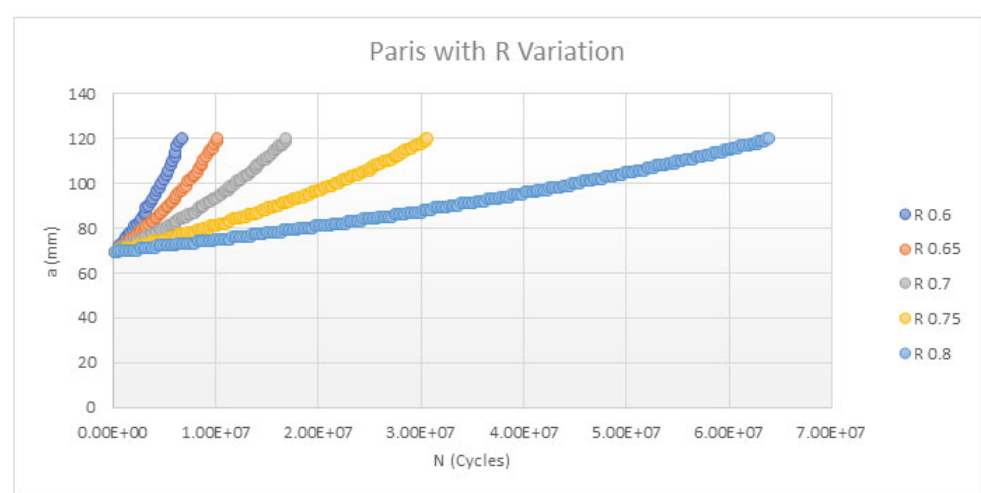

Fig. 7. Graph a vs $\mathrm{N}$ of Paris equations with variations of $\sigma_{\max }$ 
From table 2-7, the results in Matlab, and Figure 7, it is found that:

a. The greater the value of $\sigma_{\min }$ or the closer to $\sigma_{\max }$, the greater the fatigue life of the material. Thus, it is endeavored that $\Delta \sigma$ is not too large.

b. Every increase in one $\sigma_{\min }$ then the number of cycles that increase is twice that of the previous cycle (the cycle increases almost 100\%).

c. The average cycle change from $\sigma_{\min } 12$ to 16 is $14,305,204.5$ times, with an average percentage of $178.2585576 \%$.

d. The structure will fail under conditions $a \geq 0.8 \mathrm{~W}$

\subsection{Walker Equation}

Table 8. Results in the Walker equation $\left(\sigma_{\max }=20\right.$ and $\left.\sigma_{\min }=12\right)$

\begin{tabular}{cccc}
\hline No & $\mathbf{a}_{\mathbf{n}}(\mathbf{m})$ & $\mathbf{a}_{\mathbf{n}}(\mathbf{m m})$ & $\mathbf{N}$ (Cycle) \\
\hline 1 & $7.00 \mathrm{E}-02$ & 70 & $0.00 \mathrm{E}+00$ \\
14 & 0.12 & $1.20 \mathrm{E}+02$ & $2,586,499$ \\
\hline
\end{tabular}

Table 9. Results in the Walker equation $\left(\sigma_{\max }=20\right.$ and $\left.\sigma_{\min }=13\right)$

\begin{tabular}{cccc}
\hline No & $\mathbf{a}_{\mathbf{n}} \mathbf{( m )}$ & $\mathbf{a}_{\mathbf{n}}(\mathbf{m m})$ & $\mathbf{N}$ (Cycle) \\
1 & $7.00 \mathrm{E}-02$ & 70 & $0.00 \mathrm{E}+00$ \\
19 & 0.12 & 120 & $3,516,364$ \\
\hline
\end{tabular}

Table 10. Results in the Walker equation $\left(\sigma_{\max }=20\right.$ and $\left.\sigma_{\min }=14\right)$

\begin{tabular}{cccc}
\hline No & $\mathbf{a}_{\mathbf{n}}(\mathbf{m})$ & $\mathbf{a}_{\mathbf{n}}(\mathbf{m m})$ & $\mathbf{N}$ (Cycle) \\
\hline 1 & $7.00 \mathrm{E}-02$ & 70 & $0.00 \mathrm{E}+00$ \\
27 & 0.12 & 120 & $5,012,696$ \\
\hline
\end{tabular}

Table 11. Results in the Walker equation $\left(\sigma_{\max }=20\right.$ and $\left.\sigma_{\min }=15\right)$

\begin{tabular}{cccc}
\hline $\mathbf{N o}$ & $\mathbf{a}_{\mathbf{n}}(\mathbf{m})$ & $\mathbf{a}_{\mathbf{n}}(\mathbf{m m})$ & $\mathbf{N}$ (Cycle) \\
\hline 1 & $7.00 \mathrm{E}-02$ & 70 & $0.00 \mathrm{E}+00$ \\
40 & 0.12 & 120 & $7,624,094$ \\
\hline
\end{tabular}

Table 12. Results in the Walker equation $\left(\sigma_{\max }=20\right.$ and $\left.\sigma_{\min }=16\right)$

\begin{tabular}{cccc}
\hline No & $\mathbf{a}_{\mathbf{n}}(\mathbf{m})$ & $\mathbf{a}_{\mathbf{n}} \mathbf{( m m )}$ & $\mathbf{N}$ (Cycle) \\
\hline 1 & $7.00 \mathrm{E}-02$ & 70 & $0.00 \mathrm{E}+00$ \\
65 & 0.12 & $1.20 \mathrm{E}+02$ & $12,737,414$ \\
\hline
\end{tabular}

Table 13. Difference in cycles in the Walker equation with variations of $\sigma_{\min }$

\begin{tabular}{ccccc}
\hline $\mathbf{N o}$ & $\mathbf{1}$ & $\mathbf{2}$ & $\mathbf{3}$ & $\mathbf{4}$ \\
\hline $\mathrm{N}$ & $2,586,499\left(\sigma_{\min } 12\right)$ & $3,516,364\left(\sigma_{\min } 13\right)$ & $5,012,696\left(\sigma_{\min } 14\right)$ & $7,624,094\left(\sigma_{\min } 15\right)$ \\
$\mathrm{N}$ & $3,516,364\left(\sigma_{\min } 13\right)$ & $5,012,696\left(\sigma_{\min } 14\right)$ & $7,624,094\left(\sigma_{\min } 15\right)$ & $12,737,414\left(\sigma_{\min } 16\right)$ \\
$\Delta \mathrm{N}$ & 929,865 & $1,496,332$ & $2,611,398$ & $5,113,320$ \\
$\mathrm{~N}$ & & $(\Delta \mathrm{N} 1+\Delta \mathrm{N} 2+\Delta \mathrm{N} 3+\Delta \mathrm{N} 4) / 4=2,537,728.75$ & \\
$\%$ & 135.9507195 & 142.5533875 & 152.095679 & 167.0679034 \\
\hline
\end{tabular}




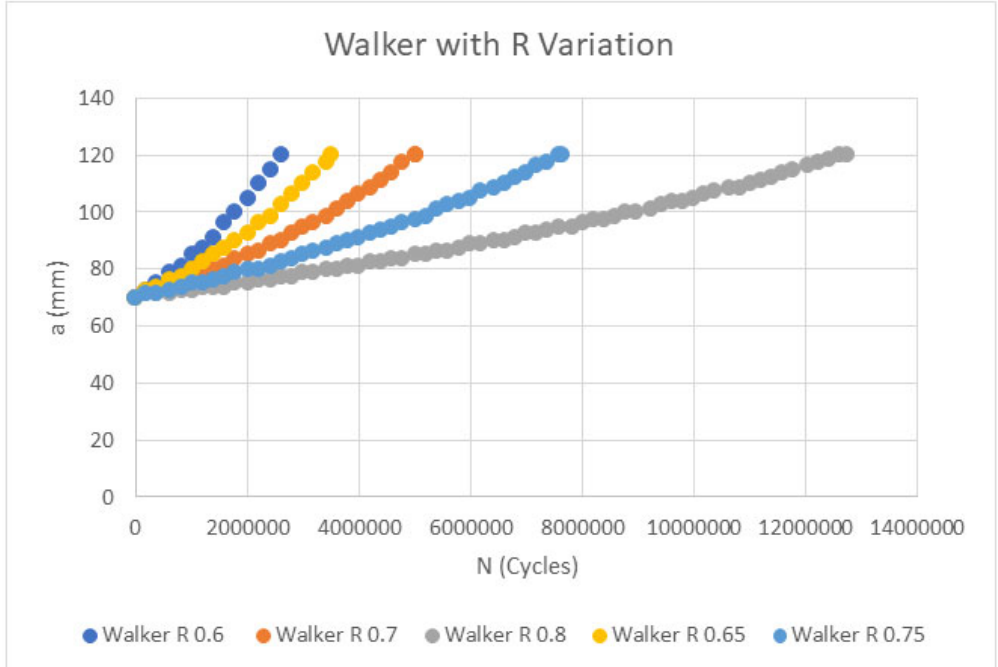

Fig. 8. Graph a vs $N$ Walker equation with $\sigma_{\max }=20$ and variation $R$

From table 8-13, the results in Matlab, and figure 8, it is found that:

a. The greater the value of $\sigma_{\min }$ or the closer to $\sigma_{\max }$, the greater the fatigue life of the material. Thus, it is endeavored that $\Delta \sigma$ is not too large.

b. Every increase in one $\sigma_{\min }$ then the number of cycles that increase is twice that of the previous cycle (the cycle increases almost $100 \%$ ).

c. The average change of cycles starting from $\sigma_{\min } 12$ to 16 is $2,537,728.75$ times with the percentage change in average $149.41692 \%$.

d. The structure will fail under conditions $a \geq 0.8 \mathrm{~W}$

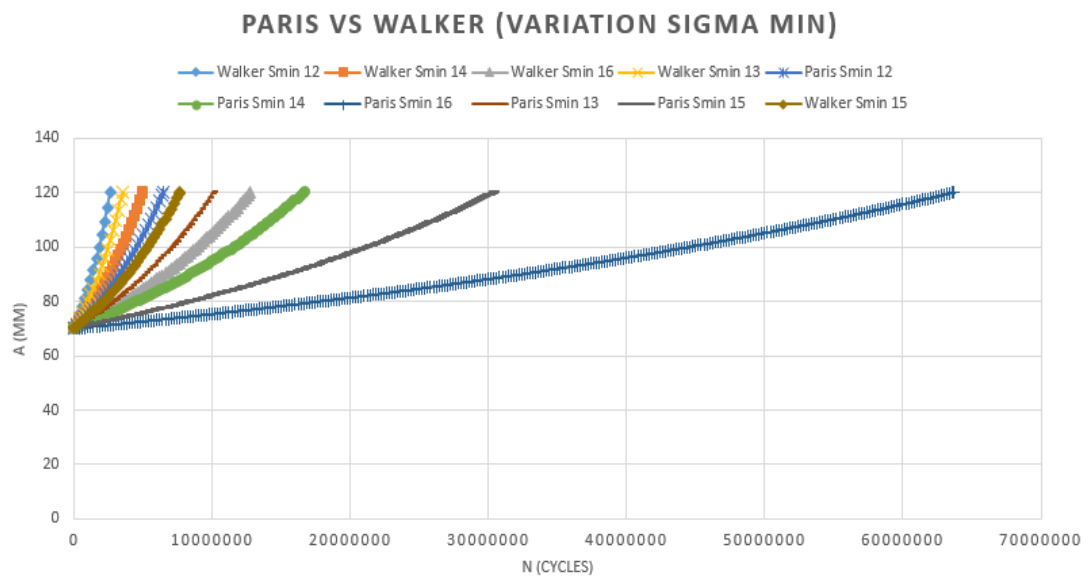

Fig. 9. Paris vs Walker graph with variations of $\sigma_{\min }$ 
Table 14. Difference in cycles in the Paris and Walker equations with variations of $\sigma_{\min }$

\begin{tabular}{|c|c|c|c|c|c|}
\hline $\boldsymbol{\sigma}_{\text {min }}$ & 12 & 13 & 14 & 15 & 16 \\
\hline Paris & $6,466,247$ & $10,046,753$ & $16,708,986$ & $30,496,373$ & $63,687,065$ \\
\hline Walker & $2,586,499$ & $3,516,364$ & $5,012,696$ & $7,624,094$ & $12,737,414$ \\
\hline$\Delta \mathbf{N}$ & $3,879,748$ & $6,530,389$ & $11,696,290$ & $22,872,279$ & $50,949,651$ \\
\hline $\mathbf{N}$ & $(\Delta \mathrm{N} 1+\Delta \mathrm{N} 2+\Delta \mathrm{N} 3+\Delta \mathrm{N} 4) / 5=19,185,671.4$ \\
\hline \multirow{2}{*}{$\%$} & $\begin{array}{c}(6,466,247 / \\
2,586,499) * 100=\end{array}$ & 285.7142 & 333.3333 & 400 & 500 \\
\cline { 2 - 6 } & 250 & 353.8095 & & \\
\hline
\end{tabular}

From figure 9 and table 14 it is found:

a. The number of cycles in the Walker equation is less than the number of cycles in the Paris equation. This is because the Walker equation takes into account the effect of stress ratio.

b. Every increase in one $\sigma_{\min }$ then the number of cycles that increase is twice that of the previous cycle (the cycle increases almost $100 \%$ ).

c. The average cycle difference in the two equations with the same $\sigma_{\min }$ value is $19,185,671.4$, and the average percentage is $353.8095 \%$ (table 14).

\section{Conclusion}

After analysis, conclusions are obtained:

a. Analysis using the Walker equation gives less fatigue life compared to the Paris equation, this is because Walker takes into account the stress ratio.

b. Analysis using the Walker equation is better because it provides predictions of fatigue life that are close to accurate because more variables are involved when compared to the Paris equation.

c. The average cycle change in the Paris equation starting from $\sigma_{\min } 12$ to 16 is $14,305,204.5$ times, with an average percentage of $178.2585576 \%$.

d. The average cycle change in the Walker equation starting from $\sigma_{\min } 12$ to 16 is $2,537,728.75$ times with a percentage change in the average of $149.41692 \%$.

e. The average cycle difference in the two equations with the same $\sigma_{\min }$ value is $19,185,671.4$, and the average percentage is $353.8095 \%$.

f. Each increase in one $\sigma_{\min }$, the number of cycles that increase is twice that of the previous cycle (the cycle increases almost 100\%) for each equation.

g. The greater the value of $\mathrm{R}$ (with a note that is varied only $\sigma_{\min }$ ), the fatigue life will be longer. Fatigue life will increase if the value of $\mathrm{R}$ gets closer to the value 1 .

h. The structure will fail with $a \geq 0.8 W(\mathrm{a}=120 \mathrm{~mm})$. 


\section{List of Symbols}

\begin{tabular}{ccl}
\hline No & Symbol & \multicolumn{1}{c}{ Annotation } \\
\hline 1 & $\mathrm{a}, \mathrm{a}_{0}$ & half the initial crack length \\
2 & $\mathrm{a}_{n}$ & half the crack length in a certain cycle \\
3 & $\mathrm{~W}$ & half width plate \\
4 & $\mathrm{~K}_{\max }$ & maximum stress intensity factor \\
5 & $\mathrm{~K}_{I C}$ & fracture toughness of material \\
6 & $\sigma_{y}$ & limit stress that is still safe for material \\
7 & $\sigma_{\max }$ & maximum stress \\
8 & $\sigma_{\min }$ & minimum stress \\
9 & $\sigma_{m}$ & mean stress \\
10 & $\Delta \sigma, \sigma_{r}$ & range of stress \\
11 & $\sigma_{a}$ & stress amplitude \\
12 & $\mathrm{R}$ & stress ratio \\
13 & $d a$ & crack growth rate \\
& $\underline{d N}$ & \\
14 & $\mathrm{Y}$ & form factor of the structure \\
15 & $C$ and $m$ & constant properties in the material \\
16 & $\mathrm{~N}$ & cycle \\
17 & $\underline{\mathrm{N}}$ & cycle average \\
18 & $\Delta \mathrm{N}$ & difference or cycle change \\
\hline
\end{tabular}

\section{Attachment}

Coding in Matlab:

disp('Crack Propagation in Material Al 2219-T87 Used Paris Equation')

$\%$ Input

$\mathrm{K} 1 \mathrm{c}=27.3 \% \mathrm{MPa}\left(\mathrm{m}^{\wedge} 0.5\right)$

$\mathrm{m}=3.30$

$\mathrm{C}=6.27 \mathrm{e}-11$

$\mathrm{w}=150 \mathrm{e}-3 \%$ setengah lebar material dalam $\mathrm{m}$

$\mathrm{YS}=395 \% \mathrm{MPa}$

ap=input('Setengah Panjang Awal Paris=');

aw=input('Setengah Panjang Awal Walker=');

$\mathrm{b}=$ input('Sigma $\max =$ ');

$\mathrm{c}=$ input('Sigma $\min =$ ');

$\mathrm{d}=\operatorname{input}(' \mathrm{Y}=$ ');

Siklus $=0$;

\%Untuk Fail saat a $>0.8 \mathrm{w}$ maka digunakan: $\mathrm{a} 0=70 \mathrm{e}-3 \mathrm{~m}$,

$\%$ Sigma_max $=20 \mathrm{MPa}\left(\mathrm{m}^{\wedge} 0.5\right)$, Sigma $\min =19,18,17,16,10 \mathrm{MPa}\left(\mathrm{m}^{\wedge} 0.5\right)$,

$\%$ Bisa juga Sigma_min $=12 \mathrm{MPa}\left(\mathrm{m}^{\wedge} 0 . \overline{5}\right)$,

Kmax_Paris $=(\mathrm{d} * \mathrm{~b} * \operatorname{sqrt}(\mathrm{pi} *(\mathrm{ap})))$;

Sigma_net_max_Paris $=\mathrm{b} *(\mathrm{w} /(\mathrm{w}-\mathrm{ap}))$;

Kmax_Walker $=(\mathrm{d} * \mathrm{~b} * \operatorname{sqrt}(\mathrm{pi} *(\mathrm{aw})))$; 


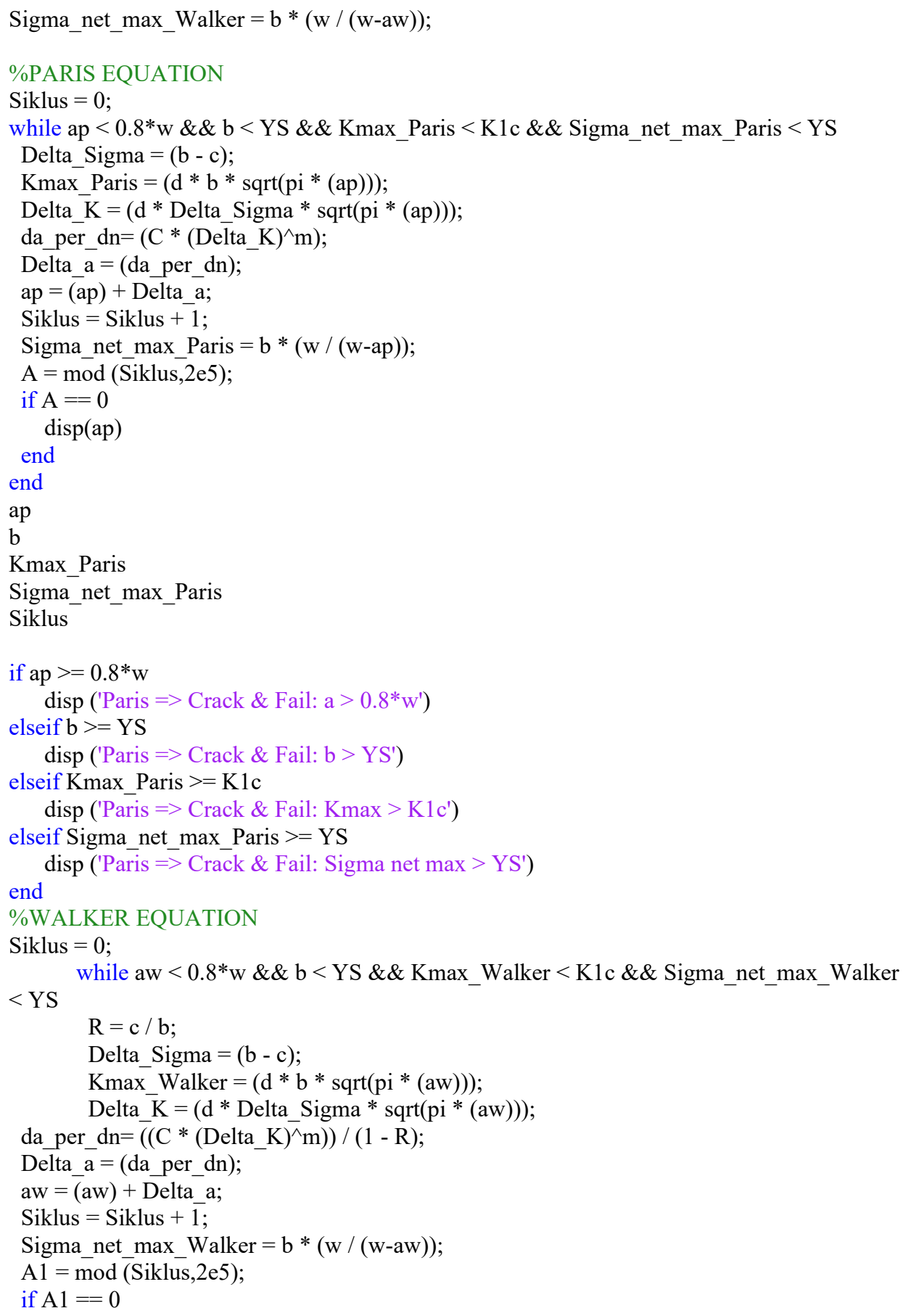




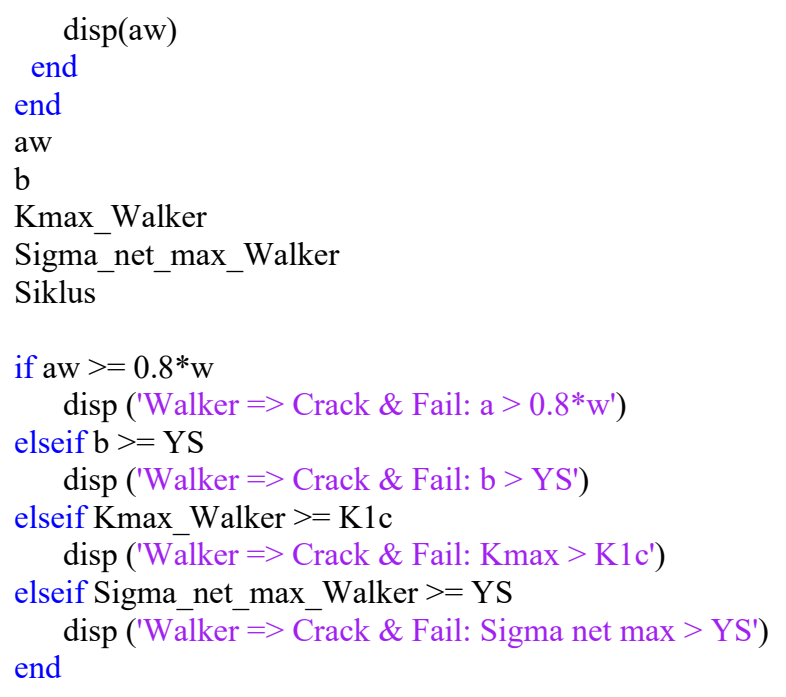

\section{References}

[1] Final Report. NTSB/AAR-89/03. 1989. Aircraft Accident Report - Aloha Airlines, Flight 243, Boeing 737-200, N73711, near Maui, Hawaii, April 28, 1988. Washington DC.

[2] E. Dieter, George. Mechanical Metallurgy, $3^{\text {rd }}$ edition, McGraw-Hill Inc. 1986.

[3] Anderson, T. L., Fracture Mechanics: Fundamentals and Applications, $3^{\text {rd }}$ edition, CRC Press, New York. 2005.

[4] Callister, W.D., Jr. , Retwisch, D.G. Materials Science and Engineering An Introduction, 7th edition., John Wiley and Sons, New York. 2007.

[5] Chandra, H. Linear Elastic Fracture Mechanics (LFEM) Fatigue, University of Sriwijaya, Palembang. 2009.

[6] Carpinteri, Alberto, Marco Paggi. Are the Pari's Law Parameters Dependent on Each Other?. Atti del Conggreso IGF 19 (2-4 Juli 2007), Milan. 2007. 